Article

\title{
Fuzzy Chaos Control of Fractional Order D-PMSG for Wind Turbine with Uncertain Parameters by State Feedback Design
}

\author{
Li Yang ${ }^{1,2} \mathbb{D}$, Fuzhao Yang ${ }^{2}$, Weitao Sheng ${ }^{2}$, Kun Zhou ${ }^{3, *}$ and Tianmin Huang ${ }^{1}$ \\ 1 School of Electrical Engineering, Southwest Jiaotong University, Chengdu 610031, China; \\ yangli@scetc.edu.cn (L.Y.); tmhuang@home.swjtu.edu.cn (T.H.) \\ 2 Electrical \& Information Engineering Department, Sichuan Engineering Technical College, \\ Deyang 618000, China; fzyang1226@163.com (F.Y.); shengweitao000@163.com (W.S.) \\ 3 College of Mechanical and Electrical Engineering, China Jiliang University, Hangzhou 310018, China \\ * Correspondence: jpwflz@163.com; Tel.: +86-134-5855-6062
}

check for updates

Citation: Yang, L.; Yang, F.; Sheng, W.; Zhou, K.; Huang, T. Fuzzy Chaos Control of Fractional Order D-PMSG for Wind Turbine with Uncertain Parameters by State Feedback Design. Energies 2021, 14, 7369. https:// doi.org/10.3390/en14217369

Academic Editor: Davide Astolfi

Received: 17 July 2021

Accepted: 19 October 2021

Published: 5 November 2021

Publisher's Note: MDPI stays neutral with regard to jurisdictional claims in published maps and institutional affiliations.

Copyright: (c) 2021 by the authors. Licensee MDPI, Basel, Switzerland. This article is an open access article distributed under the terms and conditions of the Creative Commons Attribution (CC BY) license (https:// creativecommons.org/licenses/by/ $4.0 /$ )

\begin{abstract}
To research the chaotic motion problem of the direct-drive permanent magnet synchronous generator (D-PMSG) for a wind turbine with uncertain parameters and fractional order characteristics, a control strategy established upon fuzzy state feedback is proposed. Firstly, according to the working mechanism of D-PMSG, the Lorenz nonlinear mathematical model is established by affine transformation and time transformation. Secondly, fractional order nonlinear systems (FONSs) are transformed into linear sub-model by Takagi-Sugeno (T-S) fuzzy model. Then, the fuzzy state feedback controller is designed through Parallel Distributed Compensation (PDC) control principle to suppress the chaotic motion. By applying the fractional Lyapunov stability theory (FLST), the sufficient conditions for Mittag-Leffler stability are formulated in the format of linear matrix inequalities (LMIs). Finally, the control performance and effectiveness of the proposed controller are demonstrated through numerical simulations, and the chaotic motions in D-PMSG can be eliminated quickly.
\end{abstract}

Keywords: direct-drive permanent magnet synchronous generator (D-PMSG); wind turbine; fractional order nonlinear system (FONS); fuzzy control; chaos; Mittag-Leffler stability; uncertain parameters

\section{Introduction}

With the rapid development of the global economy, fossil energy will produce a lot of pollutants and $\mathrm{CO}_{2}$ in the process of development and utilization, which will lead to global warming and pose a serious threat to the ecological environment [1]. European Public Health Alliance (EPHA) [2] reminds us that the exhaust emissions from gasoline engine combustion are still at the "dangerous" level. In the COVID-19 epidemic prevention and control process, it may endanger the most vulnerable people and even cause them respiratory failure. Therefore, it is very necessary to find a kind of green renewable energy to reduce environmental pollution without affecting global warming. As a very promising green energy, wind energy is an effective way to solve the increasingly prominent energy and environmental problems. It is also one of the green renewable energy with the most mature technology, the fastest development speed, and the largest development scale [3]. According to the statistics of the Global Wind Energy Council (GWEC) [4], the total installed capacity of wind power in the world is $651 \mathrm{GW}$, and the new installed capacity is $60.4 \mathrm{GW}$ by the end of 2019. At present, there are mainly two types of wind turbine systems (WTSs): doubly fed induction generator (DFIG) [5,6] and permanent magnet synchronous generator (PMSG) $[7,8]$ in the market. Compared with DFIG, D-PMSG has the advantages of less maintenance cost, less mechanical loss, and high service life because of its direct connection with WTSs. However, D-PMSG is a typical nonlinear complex system with strong coupling. Under certain working conditions or within some system parameters, there will be chaotic phenomena such as systematic irregular intermittent oscillation of motor speed or torque, poor control performance, and so on $[9,10]$. During the operation 
of the WTSs, there are inevitably uncertain parameters and nonlinear characteristics. It is worth noting that intensive efforts have been devoted to the research of uncertain nonlinear systems [11,12]. The output power of WTSs will have violent oscillation and fluctuation, which will have a great impact on the power grid, and even lead to the collapse of WTSs. To solve these problems, it is necessary to concentrate on the investigation of the chaotic motion of WTSs. Now a lot of research results have been obtained in the chaotic characteristic analysis and chaos control of D-PMSG for WTSs [13-19]. In recent years, fractional calculus has been gradually adopted in many engineering applications. In the actual working process, the dielectric material inside the capacitor showed fractionalorder characteristics, which was confirmed in 1983 [20]. Through the analysis of the storage and memory characteristics of the actual capacitance, the fractional-order of the capacitance-voltage equation in different dielectric materials was tested, and the inductors were also pointed to have fractional-order characteristics in 1994 [21]. By studying the charge and discharge memory properties of the resistor, capacitor, and inductor in the actual working process, the RLC circuit presented non-integer order characteristics in a certain range of parameters or certain operating conditions [22], and the fractional calculus theory was used to describe the memory characteristics of RLC circuit [23]. Through the experimental data and identification algorithms, the modeling method of the timedomain fractional-order model of permanent magnet synchronous motor (PMSM) was proposed [24]. The chaotic characteristics of fractional order PMSM were analyzed by three-phase diagrams, Lyapunov exponent spectrum, and poincaré maps [25]. To study the chaotic behavior of fractional order PMSM, many scholars have studied how to control chaos and design more control methods, such as backstepping control [26], sliding mode variable structure control [27], fuzzy control [28], state feedback control [29], and so on. Among these control methods, the design method of state feedback control is simpler, the control performance is better, and the dynamic response is faster, which can better suppress the chaos phenomenon and achieve the desired effect. The chaos motion of D-PMSG was found for the first time in 2009 [30], and the chaos modeling and dynamic characteristics analysis of D-PMSG has received much attention among researchers [31,32]. A backstepping adaptive control algorithm was proposed to suppress the influence of parameter uncertainty and wind speed disturbance on the operation performance of DPMSG [33]. To effectively improve the chaos control performance of D-PMSG, a nonlinear proportional control method was proposed [34]. Aiming at the chaotic behavior of PMSG, an adaptive dynamic programming method based on cloud radial basis function neural network was adopted to track the maximum wind energy point so that the system can quickly get rid of chaotic motion [35]. Given the above PMSG are nonlinear systems, T-S fuzzy model was applied to model the D-PMSG nonlinear system, and a new fuzzy tracker was designed to eliminate the chaotic motion effectively [36]. Based on the above literature researches, it is obvious that these studies are carried out in the integer-order region, but the WTSs is also a nonlinear system with fractional order characteristics. The relationship between fractional order and integer order of PMSG was revealed, the fractional-order mathematical model was established and its chaotic dynamic behavior was analyzed in detail [37]. The dynamic characteristics from Hoff bifurcation to stability were studied, and a new predictive control method was designed to suppress the chaotic behavior in the fractional-order model [38]. The eigenvalue, Lyapunov exponent, bifurcation, and phase diagram of the fractional-order PMSG were studied, and a self-adaptive controller was designed [39]. It is worth noting that these researches are all about the chaotic behavior of the wind turbine nonlinear system (WTNS), and the scholars rarely study the chaotic behavior analysis and control of linear fractional order D-PMSG. The challenging task is to design the suitable controller for WTNS, several control methods can be used to deal with the nonlinear system and transform it into a linear model without affecting the system properties, such as the Jacobian method [40], T-S fuzzy technology [41], highorder approximate linearization [42], etc. As a convenient and reliable tool, T-S fuzzy technology can transform a nonlinear model into a linear sub-model in an effective way. 
Given tremendous results on the T-S fuzzy model, numerous control algorithms on FONSs are reported [43-45]. Up till the present moment, lots of control algorithms through the T-S fuzzy model were applied to WTSs [46-50]. An improved augmented T-S fuzzy control is applied to wind energy conversion systems (WECSs) [46]. For the stabilization problem of nonlinear chaotic PMSG, the observer-based event-triggered fuzzy integral sliding mode controller is proposed [47]. A disturbance observer-based integral fuzzy slidingmode controller is presented for WTSs with a nonlinear PMSG by T-S fuzzy model [48]. However, the fractional-order characteristics and parameters uncertainty aren't considered in the above researches. A novel T-S fractional-order fuzzy logic controller is presented for D-PMSG based WTSs [49]. A novel adaptive fractional fuzzy integral sliding mode control scheme is proposed to suppress the chaotic motion of fractional order PMSM based WECSs [50], but the uncertain parameters in the process of the system operation are not considered.

Therefore, it is necessary to study the nonlinear dynamic behavior, chaos generation mechanism, and control method of D-PMSG for wind turbines with uncertain parameters. At present, most of the researches mainly focuses on integer order nonlinear model, and fractional order D-PMSG still needs further research. The fractional-order D-PMSG with local linearization of the T-S model can reduce the complexity of chaotic controller design and expand the system stability region. It is of great theoretical significance to build a fractional-order D-PMSG linearization sub-model and study its chaos control method so that WTSs can operate safely and stably, which lays a theoretical foundation for the further study of its chaotic dynamic characteristics and control strategy in the actual operation process. Using fuzzy PDC technology, fuzzy controller and system model have the same membership function and fuzzy rule numbers, which facilitates the stability analysis of the fuzzy system. The state feedback controller via PDC has a simple design method, good control performance, and fast dynamic response. In this paper, the chaotic motion of fractional order D-PMSG with uncertain parameters is studied, and the T-S model is applied to establish its fractional-order fuzzy linear sub-model. By PDC control technology, a fuzzy state feedback controller is designed. Based on FLST, a sufficient condition for Mittag-Leffler stability of fractional-order D-PMSG with uncertain parameters is obtained. The simulation results show that the proposed controller has good control performance and robustness, and can effectively eliminate the chaotic motion.

\section{Preliminaries and D-PMSG Mathematical Model}

\subsection{Preliminaries}

For any positive real number $\alpha \in(0,1]$, the Caputo fractional integral of a continuous function $f(t)$ can be defined as follows [51]:

$$
D_{t}^{-\alpha} f(t)=\frac{1}{\Gamma(\alpha)} \int_{t_{0}}^{t}(t-s)^{\alpha-1} f(s) d s
$$

wherein, $n-1 \leq \alpha \leq n, \alpha \in R, n \in N$.

In practical engineering application, the Caputo's derivative whose initial condition is the same as the integer-order derivative has a clearer physical meaning. The Caputo fractional order derivative with $\alpha>0$ for a continuous function $f(t)$ is defined as [51]

$$
D_{t}^{\alpha} f(t)=\frac{d^{\alpha} f(t)}{d t^{\alpha}}=\frac{1}{\Gamma(n-\alpha)} \int_{t_{0}}^{t}(t-s)^{n-\alpha-1} f^{(n)}(s) d s
$$

Lemma 1 ([52]). Given any matrices $Y, Z, N(t)$ and $M$ of appropriate dimensions and with $M$ symmetrical, then the inequation $M+Y N(t) Z+Z^{T} N^{T}(t) Y^{T}<0$ holds for any $N(t)$ satisfying $N^{T}(t) N(t) \leq I$ if and only if there exists a positive constant $\eta$, such that $M+\eta Y Y^{T}+$ $\eta^{-1} Z Z^{T}<0$. 
Lemma 2 ((Schur complement) [53]). For a given matrix $S=S^{T}$, the following three assertions are equivalent:

(1). $\quad S=\left[\begin{array}{ll}S_{11} & S_{12} \\ S_{21} & S_{22}\end{array}\right]<0$;

(2). $S_{11}<0, S_{22}-S_{12}^{T} S_{11}^{-1} S_{12}<0$;

(3). $S_{22}<0, S_{11}-S_{12} S_{22}^{-1} S_{12}^{T}<0$.

Lemma 3 ((Fractional Order Lyapunov Direct Method, FOLDM) [54]). If $x_{e}=0$ is an equilibrium point for the fractional-order system $D_{t}^{\alpha} x(t)=f(t, x)$ and $\Omega \subset R^{n}$ is a domain containing the origin. Let a continuously differentiable function $V(t, x(t)):[0, \infty) \times \Omega \rightarrow R$ be locally Lipschitz with respect to $x$. If there exist the any positive constants $l_{1}, l_{2}, l_{3}, m, n$ and $V(t, x(t))$, which satisfies the following conditions:

$$
\begin{gathered}
l_{1}\|x\|^{m} \leq V(t, x(t)) \leq l_{2}\|x\|^{m n} \\
D_{t}^{\alpha} V(t, x(t)) \leq-l_{3}\|x\|^{m n}
\end{gathered}
$$

then the equilibrium $x_{e}=0$ is said to stable via Mittag-Leffler sense. Here, $t \geq 0, \alpha \in(0,1]$. If (3) and (4) hold globally on $R^{n}$, then $x_{e}=0$ is globally Mittag-Leffler stable.

Lemma 4 ([55]). Consider the Caputo fractional-order system $D_{t}^{\alpha} x(t)=f(t, x)$, and construct the Lyapunov function $V(x(t))=2 x^{T}(t) x(t)$, then there is a constant $\xi>0$ such that the following inequality holds:

$$
D_{t}^{\alpha} V(x(t)) \leq\left(D_{t}^{\alpha} x(t)\right)^{T} x(t)+x^{T}(t)\left(D_{t}^{\alpha} x(t)\right)+\xi\|x(t)\|^{2}
$$

wherein, $t \geq 0$ and $x \in R^{n}$.

Lemma 5 ([56]). The autonomous fractional-order system $D_{t}^{\alpha} x(t)=f(t, x)$ with $\alpha \in(0,1]$ and $x \in R^{n}$ is asymptotically stable if and only if $\min _{i}\left\{\left|\arg \left(\lambda_{i}\right)\right|\right\}>\alpha \pi / 2$ is satisfied for all eigenvalues $\lambda_{i}$ of its Jacobian matrix $J=\partial f / \partial x$.

\subsection{Integer-Order Nonlinear Mathematical Model}

The output power that can be extracted from the wind is expressed as $[57,58]$ :

$$
P_{r}=0.5 C_{p} \rho \pi r^{2} v^{3}
$$

wherein, $P_{r}$ is the output power of wind turbine, $\rho$ is the air density, $r$ is the blade radius of wind turbine, $v$ is wind speed, $C_{p}$ is the wind power coefficient. The wind power conversion coefficient $C_{p}$ is a nonlinear function of the tip speed ration $\vartheta$ and the pitch angle $\beta$. The tip speed ratio $\vartheta$ can be described as follows:

$$
\vartheta=\frac{\omega_{r} r}{v}
$$

wherein, $\omega_{r}$ is the wind turbine angular speed.

For a surface mounted PMSG, the expressions of stator winding voltage and flux linkage in d-q synchronous rotation coordinate are as follows [59]:

The stator voltage equations:

$$
\left[\begin{array}{l}
u_{d} \\
u_{q}
\end{array}\right]=-\left[\begin{array}{ll}
R & 0 \\
0 & R
\end{array}\right]\left[\begin{array}{l}
i_{d} \\
i_{q}
\end{array}\right]+\left[\begin{array}{cc}
-L p & \omega_{e} L \\
-\omega_{e} L & -L p
\end{array}\right]\left[\begin{array}{l}
i_{d} \\
i_{q}
\end{array}\right]+\left[\begin{array}{c}
0 \\
\omega_{e} \psi_{f}
\end{array}\right]
$$

The stator flux linkage equations:

$$
\left[\begin{array}{l}
\psi_{d} \\
\psi_{q}
\end{array}\right]=-\left[\begin{array}{ll}
L & 0 \\
0 & L
\end{array}\right]\left[\begin{array}{l}
i_{d} \\
i_{q}
\end{array}\right]+\left[\begin{array}{c}
\psi_{f} \\
0
\end{array}\right]
$$


wherein, $u_{d, q}, i_{d, q}$ and $\psi_{d, q}$ are the stator voltages, the stator currents, and the stator flux linkage components in $\mathrm{d}-\mathrm{q}$ synchronous rotating coordinate system respectively. $L=L_{d}=L_{q}$ is the inductance of surface-mounted generator. $\psi_{f}$ is the flux linkage of permanent magnet, $R$ is the stator resistance and $\omega_{e}$ is the generation angular speed, $p$ is the differential operator $d / d t$.

The expression of electromagnetic torque can be expressed as:

$$
T_{e}=1.5 n_{p} \psi_{f} i_{q}
$$

The motion equation of D-PMSG is given by the following equation:

$$
T_{m}=T_{e}+J \frac{d \omega_{g}}{d t}+B_{m} \omega_{g}
$$

wherein, $T_{m}$ is the generation mechanical torque (since wind turbine and generator are directly connected by a shaft, i.e., $\left.T_{m} \approx T_{r}=\rho \pi r^{3} C_{p}(\vartheta, \beta) v^{2} / 2 \vartheta\right)$. J is the equivalent inertia, $B_{m}$ is the rotational damping, and $n_{p}$ is the pole pairs. $\omega_{g}$ is generator angular speed. Since D-PMSG is direct-drive and does not include the gear box, i.e., $\omega_{g} \approx \omega_{r}$ and $\omega_{e}=n_{p} \omega_{g}$.

Then the mathematical model of D-PMSG in synchronous rotating d-q axis can be described as follows [30]:

$$
\left\{\begin{array}{l}
\frac{d i_{d}}{d t}=-\frac{R}{L} i_{d}+n_{p} i_{q} \omega_{g}+\frac{u_{d}}{L} \\
\frac{d i_{q}}{d t}=-\frac{R}{L} i_{q}-n_{p} i_{d} \omega_{g}-\frac{n_{p} \psi_{f}}{L} \omega_{g}+\frac{u_{q}}{L} \\
\frac{d \omega_{g}}{d t}=\left(T_{e}-T_{m}-B_{m} \omega_{g}\right) / J
\end{array}\right.
$$

By affine transformation $x=\varsigma \widetilde{x}$ and time transformation $t=\tau \widetilde{t}$, let $x=\left[i_{d}, i_{q}, \omega_{g}\right]^{\mathrm{T}}$ and $\widetilde{x}=\left[\tilde{i}_{d}, \widetilde{i}_{q}, \widetilde{\omega}_{g}\right]^{\mathrm{T}}$, the dimensionless Lorenz chaotic model can be obtained from Equation (12) [36]:

$$
\left\{\begin{array}{l}
\frac{d \widetilde{d}_{d}}{d \widetilde{t}}=-\widetilde{i}_{d}+\widetilde{i}_{q} \widetilde{\omega}_{g}+\widetilde{u}_{d} \\
\frac{d \widetilde{i_{q}}}{d \bar{t}}=-\widetilde{i}_{q}-\widetilde{i}_{d} \widetilde{\omega}_{g}+\mu \widetilde{\omega}_{g}+\widetilde{u}_{q} \\
\frac{d \widetilde{\omega}_{g}}{d \tilde{t}}=\sigma\left(\widetilde{i}_{q}-\widetilde{\omega}_{g}\right)-\widetilde{T}_{m}
\end{array}\right.
$$

wherein, $\varsigma_{1}=\varsigma_{2}=B_{m} /\left(\tau \psi_{f} n_{p}^{2}\right), \varsigma_{3}=1 / \tau n_{p}, \tau=L / R, \sigma=\tau B_{m} / J, \mu=-\left(3 \tau n_{p}^{2} \psi_{f}^{2}\right) /(2$ $\left.B_{m} L\right), \widetilde{u}_{d}=\tau u_{d} / \varsigma_{1} L, \widetilde{u}_{q}=\tau u_{q} / \varsigma_{1} L, \widetilde{T}_{m}=\tau T_{m} / \varsigma_{3} J, \sigma$ and $\mu$ are system parameters. $\widetilde{i}_{d}, \widetilde{i}_{q}$ and $\widetilde{\omega}_{g}$ are d-q axis current component and generator speed. $\widetilde{u}_{d}, \widetilde{u}_{q}$ and $\widetilde{T}_{m}$ are d-q axis voltage component and generator torque.

In the D-PMSG chaotic model (13), it can be found that and only depend on the system parameters.

\subsection{Fractional-Order Nonlinear Mathematical Model}

Considering the fractional-order dynamic effect caused by the internal damping of the generator, the fractional-order D-PMSG chaotic model with uncertain parameters is established:

$$
\left\{\begin{array}{l}
D_{t}^{\alpha} x_{1}=-x_{1}+x_{2} x_{3}+\widetilde{u}_{d} \\
D_{t}^{\alpha} x_{2}=-x_{2}-x_{1} x_{3}+\mu x_{3}+\widetilde{u}_{q} \\
D_{t}^{\alpha} x_{3}=\sigma\left(x_{2}-x_{3}\right)-\widetilde{T}_{m}
\end{array}\right.
$$

wherein, $x=\left[x_{1}, x_{2}, x_{3}\right]^{\mathrm{T}}=\left[\widetilde{i}_{d}, \widetilde{i}_{q}, \widetilde{\omega}_{g}\right]^{\mathrm{T}}$ is a 3-dimensional state vector, $u=\left[\widetilde{u}_{d}, \widetilde{u}_{q}, \widetilde{T}_{r}\right]^{\mathrm{T}}$ is the input vectors, $\sigma$ and $\mu$ represent the system parameters, here $\sigma \in\left[\sigma_{1}, \sigma_{2}\right], \mu \in\left[\mu_{1}, \mu_{2}\right]$. 


\subsection{Fractional-Order T-S Fuzzy Model}

Considering the FONS for D-PMSG with system parameters uncertainty (14), the vector form is described as

$$
\begin{aligned}
& D_{t}^{\alpha} x(t)=A x(t)+\Phi(x(t))+B u(t) \\
& A=\left[\begin{array}{ccc}
-1 & 0 & 0 \\
0 & -1 & \mu \\
0 & \sigma & -\sigma
\end{array}\right], \Phi(x(t))=\left[\begin{array}{c}
x_{2} x_{3} \\
-x_{1} x_{3} \\
0
\end{array}\right]
\end{aligned}
$$

wherein, $x=\left[x_{1}, x_{2}, x_{3}\right]^{\mathrm{T}}=\left[\widetilde{i}_{d}, \widetilde{i}_{q}, \widetilde{\omega}_{g}\right]^{\mathrm{T}}$ is the state vector, $u=\left[\widetilde{u}_{d}, \widetilde{u}_{q}, \widetilde{T}_{r}\right]^{\mathrm{T}}$ is the input vector, $\sigma$ and $\mu$ represent the system parameters uncertainty, and the matrix $A$ is uncertain matrix with $\sigma \in\left[\sigma_{1}, \sigma_{2}\right]$ and $\mu \in\left[\mu_{1}, \mu_{2}\right]$.

Applying T-S fuzzy membership rules, the vector model (15) is transformed into equivalent linear sub-models, and then the global model is obtained by fusing these linear sub-models. The vector forms with fractional order by T-S fuzzy method can be obtained as following.

Plant rule $i$ : If $\widetilde{\omega}_{g}$ is $M_{i}$, Then

$$
D_{t}^{\alpha} x(t)=\left(A_{i}+\Delta A_{i}\right) x(t)+\left(B_{i}+\Delta B_{i}\right) u(t), i=1,2, \cdots r
$$

wherein, $x$ and $u$ are the state vector and the control input respectively. $\widetilde{\omega}_{g}$ and $M_{i}$ are $(i=1,2, \cdots, r)$ respectively the premise variables and the fuzzy sets. $i$ and $r$ represent the $i$-th rule and fuzzy membership rule numbers respectively. $A_{i}$ and $B_{i}$ are the system parameter matrix, $\Delta A_{i}$ and $\Delta B_{i}$ represent real-valued function matrices with the uncertainties of the time-varying parameters and have the following forms:

$$
\left[\Delta A_{i}, \Delta B_{i}\right]=\left[D_{A i} F_{A i}(t) E_{A i}, D_{B i} F_{B i}(t) E_{B i}\right]
$$

wherein, $D_{A i}, D_{B i}, E_{A i}$ and $E_{B i}$ are constant matrices with proper dimension. $F_{A i}(t)$ and $F_{B i}(t)$ are uncertain function matrixes with Lebesgue measurable elements and satisfy $F_{A i}^{T}(t) F_{A i}(t) \leq I$ and $F_{B i}^{T}(t) F_{B i}(t) \leq I$.

The global fractional order T-S fuzzy model with uncertain parameters can be inferred as follows:

$$
\begin{gathered}
D_{t}^{\alpha} x(t)=\sum_{i=1}^{r} h_{i}\left(\widetilde{\omega}_{g}\right)\left[\left(A_{i}+\Delta A_{i}\right) x(t)+\left(B_{i}+\Delta B_{i}\right) u(t)\right], \\
=\sum_{i=1}^{r} h_{i}\left(\widetilde{\omega}_{g}\right)\left[\bar{A}_{i} x(t)+\bar{B}_{i} u(t)\right], i=1,2, \cdots, r
\end{gathered}
$$

wherein, $h_{i}\left(\widetilde{\omega}_{g}(t)\right)=M_{i}\left(\widetilde{\omega}_{g}(t)\right) / \sum_{i=1}^{r} M_{i}\left(\widetilde{\omega}_{g}(t)\right)$ are the membership functions, and satisfying the following condition, $M_{i}\left(\widetilde{\omega}_{g}(t)\right) \geq 0, \sum_{i=1}^{r} M_{i}\left(\widetilde{\omega}_{g}(t)\right)>0, h_{i}\left(\widetilde{\omega}_{g}(t)\right) \geq 0$, $\sum_{i=1}^{r} h_{i}\left(\widetilde{\omega}_{g}(t)\right)=1$.

\section{Fuzzy Chaos Control for Fractional-Order D-PMSG}

\subsection{Fuzzy State Feedback Controller Scheme}

The fuzzy state feedback control scheme is presented as

Control rule $i$ : If $\widetilde{\omega}_{g}$ is $M_{i}$, Then

$$
u(t)=-K_{i} x(t), i=1,2, \cdots r
$$

The state feedback controller can be expressed as

$$
u(t)=-\sum_{i=1}^{r} h_{i}\left(\widetilde{\omega}_{g}\right) K_{i} x(t), i=1,2, \cdots, r
$$


By substituting the above control law into Equation (18), the closed-loop fuzzy model of fractional order D-PMSG with uncertain parameters can be described as

$$
\begin{gathered}
D_{t}^{\alpha} x(t)=\sum_{i=1}^{r} \sum_{i=1}^{r} h_{i} h_{j}\left(A_{i}-B_{i} K_{j}+\Delta A_{i}-\Delta B_{i} K_{j}\right) x(t) \\
=\sum_{i=1}^{r} \sum_{i=1}^{r} h_{i} h_{j}\left[H_{i j} x(t)\right]=\sum_{i=1}^{r} \sum_{i=1}^{r} h_{i} h_{j} H x(t) \\
i=1,2, \cdots, r, j=1,2, \cdots, r
\end{gathered}
$$

wherein, $h_{i} h_{j}=h_{i}\left(\widetilde{\omega}_{g}\right) h_{j}\left(\widetilde{\omega}_{g}\right), H_{i j}=A_{i}-B_{i} K_{j}+\Delta A_{i}-\Delta B_{i} K_{j}$.

\subsection{Mittag-Leffler Stability}

Theorem 1. The closed-loop fuzzy chaotic model of fractional order D-PMSG (21) with control input (20) is said to globally Mittag-Leffler stable if there exist a positive definite symmetric matrix $P$, the matrixes $K_{i}(i=1,2, \cdots, r)$, normal real constants $\gamma, \varepsilon_{i i}, \eta_{i i}, \delta_{i i}, \delta_{i j}$, $\delta_{j j}$ and $\delta_{j i}$, such that

$$
\left[\begin{array}{cccc}
\Pi_{11} & Q E_{A i}^{T} & M_{i}^{T} E_{B i}^{T} & Q \\
* & -\varepsilon_{i i} I & 0 & 0 \\
* & * & -\eta_{i i} I & 0 \\
* & * & * & -\gamma I
\end{array}\right]<0, i=1,2, \cdots, r
$$

with $\Pi_{11}=\operatorname{Sym}\left(A_{i} Q-B_{i} M_{i}\right)+\varepsilon_{i i} D_{A i} D_{A i}^{T}+\eta_{i i} D_{B i} D_{B i}^{T}$.

and

$$
\left[\begin{array}{cccccc}
\bar{\Pi}_{11} & Q E_{A i}^{T} & M_{j}^{T} E_{B i}^{T} & Q E_{A j}^{T} & M_{i}^{T} E_{B j}^{T} & Q \\
* & -\delta_{i i} I & 0 & 0 & 0 & 0 \\
* & * & -\delta_{i j} I & 0 & 0 & 0 \\
* & * & * & -\delta_{j j} I & 0 & 0 \\
* & * & * & * & -\delta_{j i} I & 0 \\
* & * & * & * & * & -\gamma I
\end{array}\right]<0,1 \leq i<j \leq r
$$

with

$\bar{\Pi}_{11}=\operatorname{Sym}\left(A_{i} Q-B_{i} M_{j}+A_{j} Q-B_{j} M_{i}\right)+\delta_{i i} D_{A i} D_{A i}^{T}+\delta_{i j} D_{B i} D_{B i}^{T}+\delta_{j i} D_{A j} D_{A j}^{T}+\delta_{j j} D_{B j} D_{B j}^{T}$. wherein, $Q=P^{-1}, M_{i}=K_{i} P^{-1}$.

Proof of Theorem 1. Define the Lyapunov function candidate $V(t, x(t))$ with a quadratic form weighted by a symmetric positive matrix $P$.

$$
V(t, x(t))=2 x^{T}(t) P x(t)
$$

According to Lemma 4, taking $\alpha$ derivative of (24), then causes

$$
D_{t}^{\alpha} V(x(t)) \leq\left(D_{t}^{\alpha} x(t)\right)^{T} P x(t)+x^{T}(t) P\left(D_{t}^{\alpha} x(t)\right)+\xi\|P\|\|x(t)\|^{2}
$$

From Lemma 3, as long as the above-mentioned inequality (25) satisfies (4), then fractional-order D-PMSG (21) is Mittag-Leffler stable with respect to the equilibrium point. Then the following inequality holds

$$
\left(D_{t}^{\alpha} x(t)\right)^{T} P x(t)+x(t)^{T} P\left(D_{t}^{\alpha} x(t)\right)+\xi\|P\|\|x(t)\|^{2} \leq-l_{3}\|x(t)\|^{2}
$$


The inequation (26) is equivalent as follows

$$
\left(D_{t}^{\alpha} x(t)\right)^{T} P x(t)+x(t)^{T} P\left(D_{t}^{\alpha} x(t)\right)+\bar{\xi}\|x(t)\|^{2} \leq 0
$$

wherein, $\bar{\xi}=\xi\|P\|+l_{3}$.

From inequation (27), the following in equation holds

$$
\begin{aligned}
& \left(D_{t}^{\alpha} x(t)\right)^{T} P x(t)+x(t)^{T} P\left(D_{t}^{\alpha} x(t)\right)+\bar{\xi}\|x(t)\|^{2} \\
& =x^{T}(t)\left(H^{T} P+P H\right) x(t)+x^{T}(t) \bar{\xi} x(t)=\sum_{i=1}^{r} \sum_{j=1}^{r} h_{i} h_{j} x^{T}(t)\left(H_{i j}^{T} P+P H_{i j}+\bar{\xi} I\right) x(t) \\
& =\sum_{i=1}^{r} h_{i}^{2} x^{T}(t)\left(H_{i i}^{T} P+P H_{i i}+\bar{\xi} I\right) x(t)+\sum_{i=1}^{r} \sum_{i<j} h_{i} h_{j} x^{T}(t)\left[\left(H_{i j}+H_{j i}\right)^{T} P+P\left(H_{i j}+H_{j i}\right)+\bar{\xi} I\right] x(t)
\end{aligned}
$$

Assuming that each part of the third equation in (28) to be negative definite, then the fractional-order D-PMSG (21) is Mittag-Leffler stable.

Firstly, suppose that the first sum of the last equation in (28) is negative definite

$$
H_{i i}^{T} P+P H_{i i}+\bar{\xi} I<0, i=1,2, \cdots, r
$$

Substituting $H_{i i}$ into inequation (29), one can get

$$
\operatorname{Sym}\left[P\left(A_{i}-B_{i} K_{i}+D_{A i} F_{A i} E_{A i}-D_{B i} F_{B i} E_{B i} K_{i}\right)\right]+\bar{\zeta} I<0, i=1,2, \cdots, r
$$

wherein, $\operatorname{Sym}(X)=X+X^{T}$.

Inequation (30) can be represented as following

$$
\operatorname{Sym}\left[P\left(A_{i}-B_{i} K_{i}\right)\right]+\operatorname{Sym}\left[P\left(D_{A i} F_{A i} E_{A i}\right)\right]+\operatorname{Sym}\left[P\left(-D_{B i} F_{B i} E_{B i} K_{i}\right)\right]+\bar{\xi} I<0
$$

Based on Lemma 1, one obtains (31) holds if and only if there exist $\varepsilon_{i i}$ and $\eta_{i i}$ with $i=1,2, \cdots, r$, such that

$\operatorname{Sym}\left[P\left(A_{i}-B_{i} K_{i}\right)\right]+\varepsilon_{i i} P D_{A i} D_{A i}^{T} P+\varepsilon_{i i}^{-1} E_{A i}^{T} E_{A i}+\eta_{i i} P D_{B i} D_{B i}^{T} P+\eta_{i i}^{-1}\left(E_{B i} K_{i}\right)^{T} E_{B i} K_{i}+\bar{\zeta} I<0$

By applying the Schur complement to (32), we have

$$
\left[\begin{array}{cccc}
\Xi_{11} & E_{A i}^{T} & \left(E_{B i} K_{i}\right)^{T} & I \\
* & -\varepsilon_{i i} I & 0 & 0 \\
* & * & -\eta_{i i} I & 0 \\
* & * & * & -\gamma I
\end{array}\right]<0, i=1,2, \cdots, r
$$

wherein, $\gamma=\bar{\zeta}^{-1}, \Xi_{11}=\operatorname{Sym}\left(P\left(A_{i}-B_{i} K_{i}\right)\right)+\varepsilon_{i i} P D_{A i} D_{A i}^{T} P+\eta_{i i} P D_{B i} D_{B i}^{T} P$.

Now, pre- and post-multiplying the above Inequation (33) by the diagonal transformation matrix, the following inequations are derived:

$$
\left[\begin{array}{cccc}
P^{-1} \Xi_{11} P^{-1} & P^{-1} E_{A i}^{T} & P^{-1}\left(E_{B i} K_{i}\right)^{T} & P^{-1} I \\
* & -\varepsilon_{i i} I & 0 & 0 \\
* & * & -\eta_{i i} I & 0 \\
* & * & * & -\gamma I
\end{array}\right]<0, i=1,2, \cdots, r
$$

Assuming $Q=P^{-1}$ and $M_{i}=K_{i} P^{-1}$ yields the LMIs (22) in Theorem 1.

The LMIs (23) can be obtained by a similar procedure. Suppose that the second sum of the last equation in (28) is negative definite

$$
\left(H_{i j}+H_{j i}\right)^{T} P+P\left(H_{i j}+H_{j i}\right)+\bar{\xi} I<0,1 \leq i<j \leq r
$$


By substituting $H_{i j}$ into the above inequation (35), we have

$$
\begin{aligned}
& \left(H_{i j}+H_{j i}\right)^{T} P+P\left(H_{i j}+H_{j i}\right)+\bar{\xi} I=\operatorname{Sym}\left(P\left(H_{i j}+H_{j i}\right)\right)+\bar{\xi} I \\
& =\operatorname{Sym}\left\{P \left[\left(A_{i}-B_{i} K_{j}+D_{A i} F_{A i} E_{A i}-D_{B i} F_{B i} E_{B i} K_{j}\right)+\right.\right. \\
& \left.\left.\left(A_{j}-B_{j} K_{i}+D_{A j} F_{A j} E_{A j}-D_{B j} F_{B j} E_{B j} K_{i}\right)\right]\right\}+\bar{\xi} I<0,1 \leq i<j \leq r
\end{aligned}
$$

Inequation (36) can be represented as following

$$
\begin{aligned}
& \operatorname{Sym}\left[P\left(A_{i}-B_{i} K_{j}+A_{j}-B_{j} K_{i}\right)\right]+ \\
& \operatorname{Sym}\left[\left(D_{A i} F_{A i} E_{A i}-D_{B i} F_{B i} E_{B i} K_{j}+D_{A j} F_{A j} E_{A j}-D_{B j} F_{B j} E_{B j} K_{i}\right)\right]+\bar{\zeta} I<0, \\
& 1 \leq i<j \leq r
\end{aligned}
$$

Based on Lemma 1, inequation (37) holds if and only if there exist $\delta_{i i}, \delta_{i j}, \delta_{j j}$, and $\delta_{j i}$ with $1 \leq i<j \leq r$, such that

$$
\begin{aligned}
& \operatorname{Sym}\left[P\left(A_{i}-B_{i} K_{j}+A_{j}-B_{j} K_{i}\right)\right]+\delta_{i i}\left(P D_{A i}\right)\left(P D_{A i}\right)^{T}+ \\
& \delta_{i i}^{-1}\left(E_{A i}^{T}\right) E_{A i}+\delta_{i j}\left(P D_{B i}\right)\left(P D_{B i}\right)^{T}+\delta_{i j}^{-1}\left(E_{B i} K_{j}\right)^{T} E_{B i} K_{j} \\
& +\delta_{j j}\left(P D_{A j}\right)\left(P D_{A j}\right)^{T}+\delta_{j j}^{-1}\left(E_{A j}^{T}\right) E_{A j}+\delta_{j i}\left(P D_{B j}\right)\left(P D_{B j}\right)^{T}+ \\
& \delta_{j i}^{-1}\left(E_{B j} K_{i}\right)^{T} E_{B j} K_{i}+\bar{\xi} I<0 \\
& 1 \leq i<j \leq r
\end{aligned}
$$

By applying the Schur complement to (38), we have

$$
\left[\begin{array}{cccccc}
\bar{\Xi}_{11} & E_{A i}^{T} & \left(E_{B i} K_{j}\right)^{T} & E_{A j}^{T} & \left(E_{B j} K_{i}\right)^{T} & I \\
* & -\delta_{i i} I & 0 & 0 & 0 & 0 \\
* & * & -\delta_{i j} I & 0 & 0 & 0 \\
* & * & * & -\delta_{j j} I & 0 & 0 \\
* & * & * & * & -\delta_{j i} I & 0 \\
* & * & * & * & * & -\gamma I
\end{array}\right]<0,1 \leq i<j \leq r
$$

wherein, $\gamma=\bar{\xi}^{-1}$,

$$
\bar{\Xi}_{11}=\operatorname{Sym}\left[P\left(A_{i}-B_{i} K_{j}+A_{j}-B_{j} K_{i}\right)\right]+\delta_{i i} P D_{A i} D_{A i}^{T} P+\delta_{i j} P D_{B i} D_{B i}^{T} P+\delta_{j j} P D_{A j} D_{A j}^{T} P+\delta_{j i} P D_{B j} D_{B j}^{T} P .
$$

Now, pre- and post-multiplying the above inequation (39) by the diagonal transformation matrix, the following inequations are derived:

$$
\left[\begin{array}{cccccc}
P^{-1} \bar{\Xi}_{11} P^{-1} & P^{-1} E_{A i}^{T} & P^{-1}\left(E_{B i} K_{j}\right)^{T} & P^{-1} E_{A j}^{T} & P^{-1}\left(E_{B j} K_{i}\right)^{T} & I \\
* & -\delta_{i i} I & 0 & 0 & 0 & 0 \\
* & * & -\delta_{i j} I & 0 & 0 & 0 \\
* & * & * & -\delta_{j j} I & 0 & 0 \\
* & * & * & * & -\delta_{j i} I & 0 \\
* & * & * & * & * & -\gamma I
\end{array}\right], 1 \leq i<j \leq r
$$

Assuming $Q=P^{-1}$ and $M_{i}=K_{i} P^{-1}$ yields the LMIs (23) in Theorem 1.

When LMIs (22) and (23) hold, the fractional-order D-PMSG fuzzy closed-loop model (21) is Mittag-Leffler stable. The proof is complete.

\section{Simulation Results}

\subsection{Simulation Parameters}

The PMSG parameters in the simulation are shown in Table 1. The wind turbine parameters are given as follows: 
the blade radius of wind turbine $r=1.12 \mathrm{~m}$, the air density $\rho=1.225 \mathrm{~kg} / \mathrm{m}^{3}$, the optimum tip speed ratio $\vartheta_{\text {opt }}=0.9$, and the optimum power coefficient $C p=0.45$.

Table 1. PMSG parameters.

\begin{tabular}{llll}
\hline System Parameter & Symbol & Unit & Value \\
\hline Direct/Quadrature inductance & $L$ & $\mathrm{mH}$ & vary \\
\hline Stator resistance & $R$ & $\Omega$ & 1.14 \\
\hline Permanent magnet flux-linkage & $\psi_{f}$ & $\mathrm{mWb}$ & vary \\
\hline Moment of inertia & $J$ & $\mathrm{~kg} \cdot \mathrm{m}^{2}$ & 0.089 \\
\hline Pole pairs & $n_{p}$ & $\mathrm{number}$ & 17 \\
\hline
\end{tabular}

\subsection{System Simulation Experiment}

Assuming that the parameters $L$ and $\psi_{f}$ change randomly in a certain range, the fractional-order D-PMSG chaotic model with uncertain parameters is studied

$$
D_{t}^{\alpha} x(t)=\bar{A} x(t)+\Phi(x(t))+\bar{B} u(t)
$$

wherein, $x(t)=\left[\tilde{i}_{d}, \widetilde{i}_{q}, \widetilde{\omega}_{g}\right]$ is the state, $u(t)$ is the control input, $\bar{A}=A+\Delta A=$ $\left[\begin{array}{ccc}-1 & 0 & 0 \\ 0 & -1 & \mu \\ 0 & \sigma & -\sigma\end{array}\right]$ and $\bar{B}=B+\Delta B$ are uncertain parameter matrices and $\Phi(x(t))=$ $\left[\begin{array}{c}x_{2} x_{3} \\ -x_{1} x_{3} \\ 0\end{array}\right]$ is nonlinear vector. The matrix $\bar{A}$ is uncertain matrix due to $\sigma \in\left[\sigma_{1}, \sigma_{2}\right]$ and $\mu \in\left[\mu_{1}, \mu_{2}\right]$.

Assuming that $\widetilde{\omega}_{g}(t) \in[-30,30]$, the fuzzy rules are described as follows:

Rule 1: If $\widetilde{\omega}_{g}$ is $M_{1}$, Then $D_{t}^{\alpha} x(t)=\bar{A}_{1} x(t)+\bar{B}_{1} u(t)$;

Rule 2: If $\widetilde{\omega}_{g}$ is $M_{2}$, Then $D_{t}^{\alpha} x(t)=\bar{A}_{2} x(t)+\bar{B}_{2} u(t)$.

When $u(t)=0$, the open-loop fuzzy model of fractional order D-PMSG can be expressed as follows:

$$
D_{t}^{\alpha} x(t)=\sum_{i=1}^{r} h_{i}\left(\widetilde{\omega}_{g}(t)\right)\left(A_{i}+\Delta A_{i}\right) x(t)
$$

During the simulation, let $\sigma=16 \pm 0.2, \mu=45.92 \pm 1$, we set $\sigma$ in the interval $[15.8,16.2]$ and set $\mu$ in the interval $[44.92,46.92]$ randomly. Then there are the following matrices.

$$
\begin{gathered}
A_{1}=\left[\begin{array}{ccc}
-1 & 30 & 0 \\
-30 & -1 & 45.92 \\
0 & 16 & -16
\end{array}\right], A_{2}=\left[\begin{array}{ccc}
-1 & -30 & 0 \\
30 & -1 & 45.92 \\
0 & 16 & -16
\end{array}\right], \Delta A_{1}=\Delta A_{2}=\left[\begin{array}{ccc}
0 & 0 & 0 \\
0 & 0 & \sin (t) \\
0 & 0.2 & -0.2
\end{array}\right], \\
D_{A i} \Delta F_{A i}(t) E_{A i}=\left[\begin{array}{ccc}
0 & 0 & 0 \\
0 & 0.0625 & 0 \\
0 & 0 & 0.2296
\end{array}\right]\left[\begin{array}{ccc}
1 & 0 & 0 \\
0 & \sin (t) & 0 \\
0 & 0 & 1
\end{array}\right]\left[\begin{array}{ccc}
0 & 0 & 0 \\
0 & 0 & 16 \\
0 & 0.871 & -0.871
\end{array}\right] . \\
\text { Then } D_{A i}=\left[\begin{array}{ccc}
0 & 0 & 0 \\
0 & 0.0625 & 0 \\
0 & 0 & 0.2296
\end{array}\right] \text { and } E_{A i}=\left[\begin{array}{ccc}
0 & 0 & 0 \\
0 & 0 & 16 \\
0 & 0.871 & -0.871
\end{array}\right] .
\end{gathered}
$$

The fuzzy membership functions are expressed as following:

$$
h_{1}\left(\widetilde{\omega}_{g}(t)\right)=\frac{1}{2}\left[1+\frac{\widetilde{\omega}_{g}(t)}{30}\right] \text { and } h_{2}\left(\widetilde{\omega}_{g}(t)\right)=\frac{1}{2}\left[1-\frac{\widetilde{\omega}_{g}(t)}{30}\right] .
$$

The system state diagrams and three-phase diagrams of the system without control are shown in Figure 1. The chaotic behavior of solutions for integer-order $\alpha=1$ is depicted in 
Figure $1 \mathrm{a}$. Figure $1 \mathrm{~b}$ shows some changes in solutions when the order is $\alpha=0.97$. Further variations $\alpha=0.96$ being going to affect the behavior of the states is shown in Figure 1c. Obviously, from Figure 1d, variations in the differential order will drastically affect the solutions to have stables for $\alpha=0.95$.

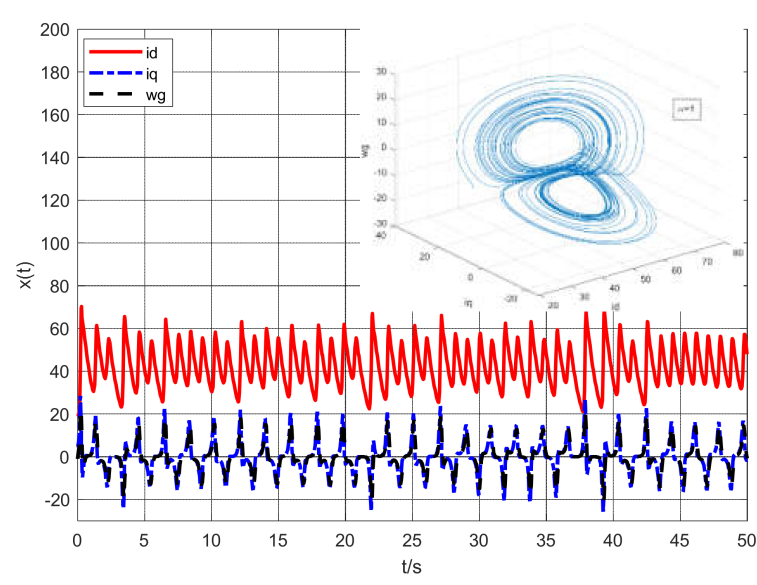

(a)

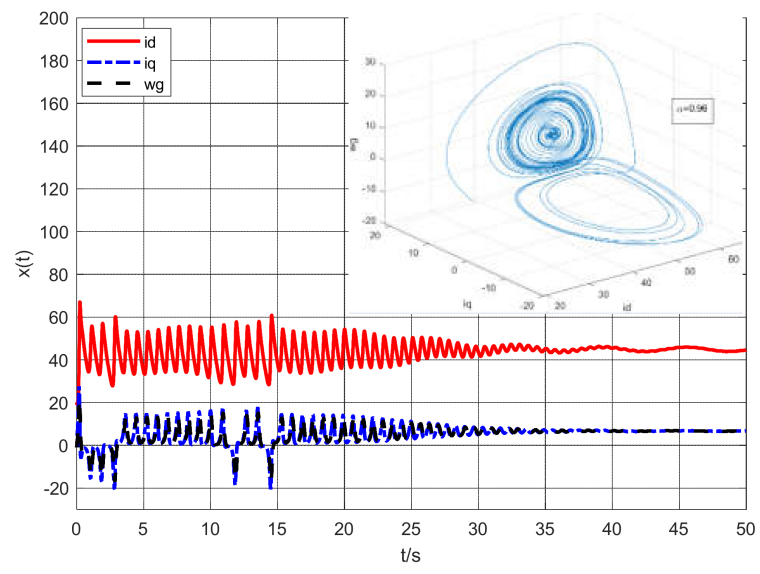

(c)

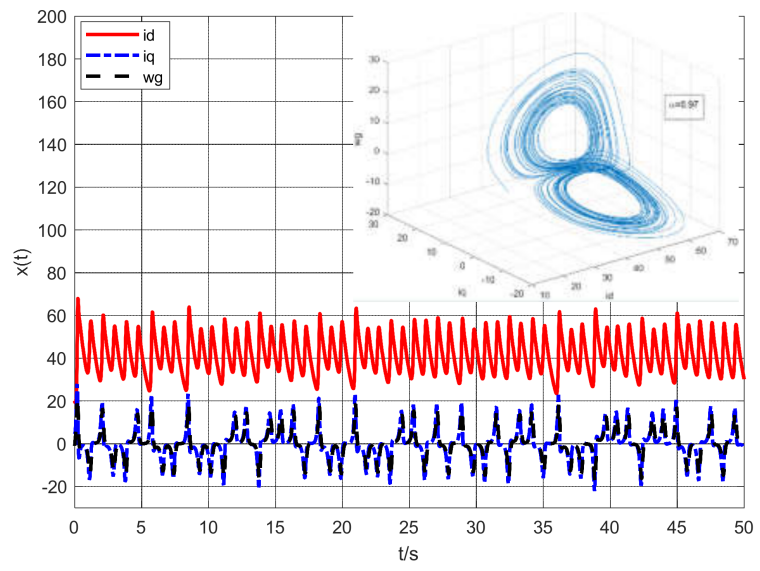

(b)

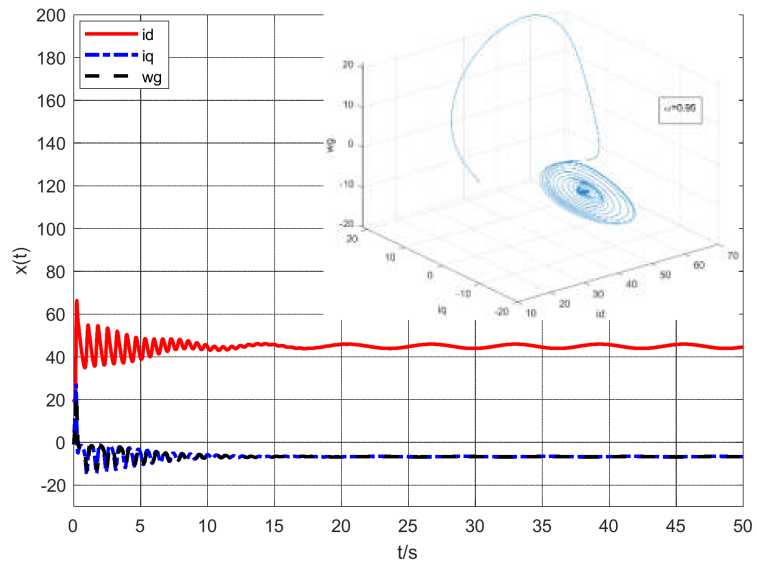

(d)

Figure 1. The chaotic characteristics of the system without control.

Using the following PDC control method, the state feedback control model is designed as follows:

Rule 1: If $\widetilde{\omega}_{g}$ is $M_{1}$, Then $u(t)=-K_{1} x(t)$;

Rule 2: If $\widetilde{\omega}_{g}$ is $M_{2}$, Then $u(t)=-K_{2} x(t)$.

The global state feedback controller is obtained

$$
u(t)=-\sum_{j=1}^{2} h_{j}\left(\widetilde{\omega}_{g}(t)\right) K_{j} x(t)
$$

Thus, the closed-loop fuzzy control model of fractional-order D-PMSG with uncertain parameters can be described as

$$
D_{t}^{\alpha} x(t)=\sum_{i=1}^{2} \sum_{j=1}^{2} h_{i}\left(\widetilde{\omega}_{g}(t)\right) h_{j}\left(\widetilde{\omega}_{g}(t)\right)\left(A_{i}-B_{i} K_{j}+\Delta A_{i}-\Delta B_{i} K_{j}\right) x(t)
$$

Giving the control amount for the load torque and quadrature axis voltage, then control input parameter is $B_{1}=B_{2}=[0 ; 1 ; 1]$ and assuming that the input parameter changes to 0 .

The inequalities in Theorem 1 are solved efficiently using the solver packages LMIs in MATLAB, the gain matrixes of fuzzy state feedback controller are as follows: $K_{1}=[6.1060,-6.1274,93.7378]$ and $K_{2}=[-6.1060,-6.1274,93.7378]$. 
It can be seen from Figure 2 that when the system parameters change randomly in a certain range and the fractional-order is different, the control system can be stabilized quickly, and the control performance and robustness are improved. Figure 3 illustrates that the fractional order also has a great influence on the control performance of the system. With the decrease of fractional order, the control performance is better.

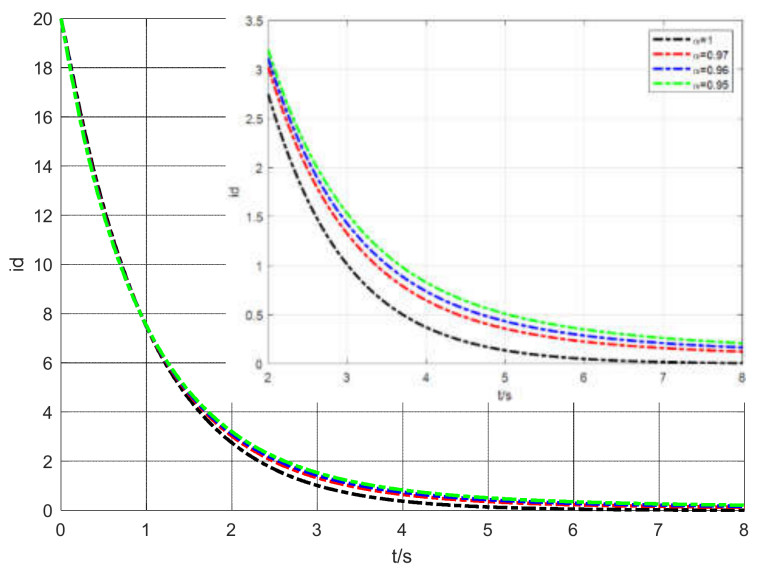

(a) The state curve of $\tilde{i}_{d}$

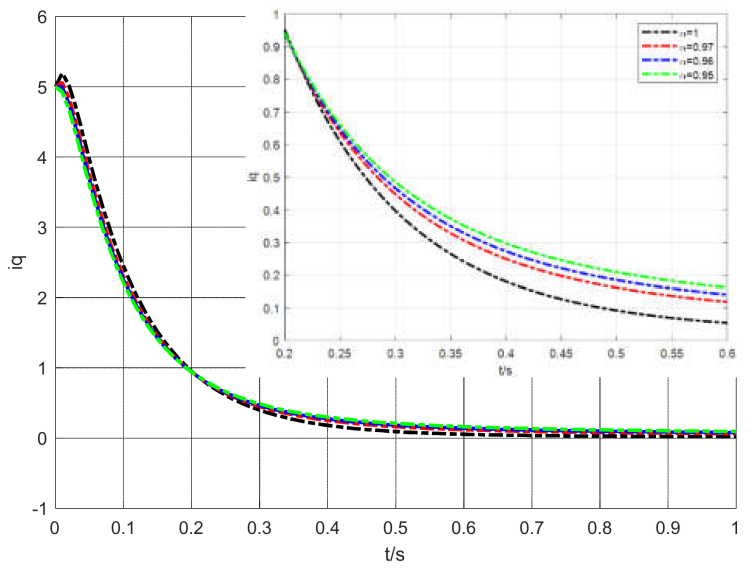

(b) The state curve of $\tilde{i}_{q}$

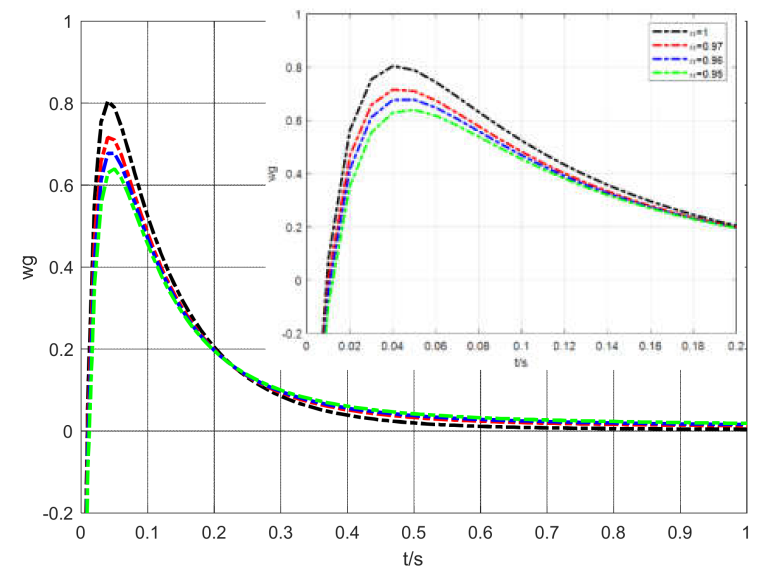

(c) The state curve of $\tilde{\omega}_{g}$

Figure 2. The control state diagram.

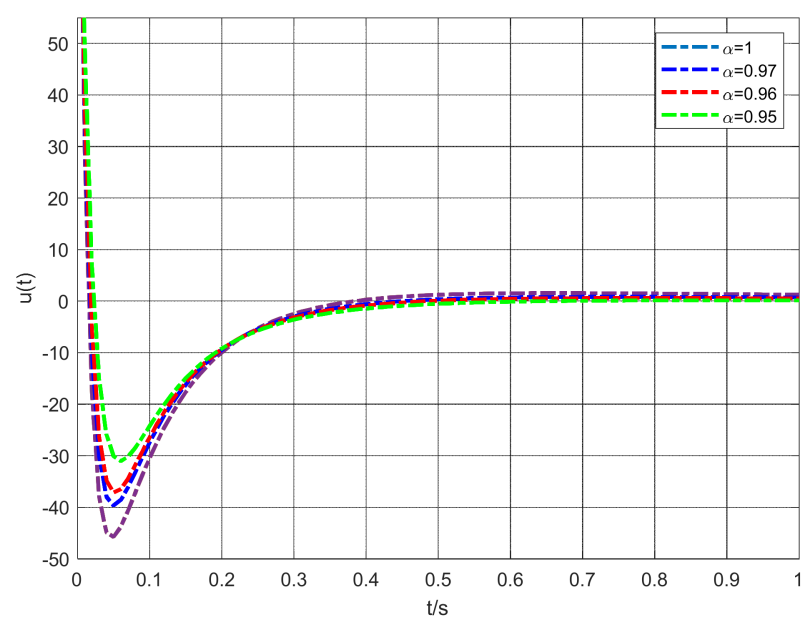

Figure 3. The system control curve. 


\section{Conclusions}

In this paper, the fractional-order D-PMSG fuzzy chaotic model with uncertain parameters is established and a fuzzy state feedback control strategy based on the PDC control method is proposed. By using FOLDM, through the properties of fractional calculus, based on Schur complement lemma, a sufficient condition for Mittag-Leffler stability is derived in LMI form. In the process of research, there is no need to give the fuzzy universe in advance, which expands the working range of fuzzy control. The simulation results show that the control method can effectively eliminate the harmful chaotic motion in D-PMSG when the system parameters are uncertain or the fractional-order changes, and has strong robustness and applicability. The theory of neutrosophic logic and sets was first proposed by Smarandache in 1995 (published in 1998) [60] which is an extension of the fuzzy logic and sets to further solve the problems of the system uncertainty and improve the control performance of the system. Neutrosophic logic uses the triplet components in the order: (truth-membership, indeterminacy-membership, and falsehood-membership), which is better descriptive than fuzzy logic. Later on, neutrosophic statistics that is the generalization of classical statistics is introduced [61]. In recent years, neutrosophic statistics have been widely investigated [62-66]. During the operation of D-PMSG, some parameters are not constants but will change with time, such as wind speed varying, major component aging, and manufacturing tolerances. To solve the uncertainty of the parameters and improve the control performance of D-PMSG, neutrosophic statistics will be applied in the modeling and control of D-PMSG in future research.

Author Contributions: T.H. and K.Z. conceived and designed the simulation; F.Y. performed the simulation; W.S. analyzed the data; L.Y. wrote the paper. All authors have read and agreed to the published version of the manuscript.

Funding: This work was funded by the National Natural Science Foundation of China (51907128) and the Deyang Science and Technology Plan Project (2019SZ80, 2021SZ005).

Conflicts of Interest: The authors declare no conflict of interest.

$\begin{array}{ll}\text { Abbreviations } \\ \begin{array}{ll}\text { D-PMSG } & \text { direct-drive permanent magnet synchronous generator } \\ \text { T-S } & \text { Takagi-Sugeno } \\ \text { FONSs } & \text { fractional order nonlinear systems } \\ \text { fractional Lyapunov stability theory }\end{array} \\ \text { PDC } & \text { parallel distributed compensation } \\ \text { LMIs } & \text { linear matrix inequalities } \\ \text { FONS } & \text { fractional order nonlinear system } \\ \text { EPHA } & \text { European Public Health Alliance } \\ \text { GWEC } & \text { Global Wind Energy Council } \\ \text { WTSs } & \text { wind turbine systems } \\ \text { DFIG } & \text { doubly-fed induction generator } \\ \text { PMSG } & \text { permanent magnet synchronous generator } \\ \text { PMSM } & \text { permanent magnet synchronous motor } \\ \text { WTNS } & \text { wind turbine nonlinear system } \\ \text { WECSs } & \text { wind energy conversion systems } \\ \text { FOLDM } & \text { fractional order Lyapunov direct method }\end{array}$

\section{References}

1. State Grid Energy Research Institute Co. LTD. Analysis Report on Energy and Power Development at Home and Abroad 2019; China Electric Power Press: Beijing, China, 2019.

2. Biological Research. The Increase of Mortality Rate of SARS coc-1 in Air Polluted Cities. Available online: http:/ / news.bioon. com/article/6752494.html (accessed on 23 March 2020).

3. Jiang, Z.Y.; Hu, W.F.; Dong, W.B.; Gao, Z.; Ren, Z.R. Structural Reliability Analysis of Wind Turbines: A Review. Energies 2017, 10, 2099. [CrossRef] 
4. National Energy Administration. Analysis on Development Status of Wind Power Industry for Global and China. Available online: https://www.sohu.com/a/415029198_813209 (accessed on 26 August 2020).

5. Li, S.Z.; Wang, H.P.; Tian, Y.; Aitouch, A.; Klein, J. Direct Power Control of DFIG Wind Turbine Systems based on an Intelligent Proportional-Integral Sliding Mode Control. ISA Trans. 2016, 64, 431-439. [CrossRef] [PubMed]

6. Nguyen, A.T.; Lee, D.C. Sensorless Control of DFIG Wind Turbine Systems based on SOGI and Rotor Position Correction. IEEE Trans. Power Electron. 2021, 36, 5486-5495. [CrossRef]

7. Worku, M.Y.; Abido, M.A.; Iravani, R. PMSG based Wind System for Real-time Maximum Power Generation and Low Voltage Ride Through. J. Renew. Sustain. Energy 2017, 9, 013304-013319. [CrossRef]

8. Mani, P.; Lee, J.H.; Kang, K.W.; Joo, Y.H. Digital Controller Design via LMIs for Direct-driven Surface Mounted PMSG-based Wind Energy Conversion System. IEEE Trans. Cybern. 2020, 50, 3056-3067. [CrossRef]

9. Ren, L.Z.; Lei, T.F.; Chen, H.; Wang, R. Optimal Control Research for the Wind Turbine PMSG Chaos Motion. Appl. Mech. Mater. 2014, 543, 1291-1295. [CrossRef]

10. Daróczy, L.; Janiga, G.; Thévenin, D. Analysis of the Performance of a H-Darrieus Rotor under Uncertainty using Polynomial Chaos Expansion. Energy 2016, 113, 399-412. [CrossRef]

11. Huynh, T.T.; Lin, C.M.; Le, N.Q.K.; Vu, M.T.; Nguyen, N.P.; Chao, F. Intelligent Wavelet Fuzzy Brain Emotional Controller Using Dual Function-Link Network for Uncertain Nonlinear Control Systems. Appl. Intell. 2021, 17, 15-23.

12. Huynh, T.T.; Lin, C.M.; Le, T.L.; Nguyen, N.P.; Hong, S.K.; Chao, F. Wavelet Interval Type-2 Fuzzy Quad-Function-Link Brain Emotional Control Algorithm for the Synchronization of 3D Nonlinear Chaotic Systems. Int. J. Fuzzy Syst. 2020, 22, $2546-2564$. [CrossRef]

13. Hemati, H. Strange Attractors in Brushless DC Motor. IEEE Trans. Circuits Syst.-I 1994, 41, 40-45. [CrossRef]

14. Li, Z.; Park, J.B.; Joo, Y.H.; Zhang, B.; Chen, G.R. Bifurcations and Chaos in a Permanent-Magnet Synchronous Motor. IEEE Trans. Circuits Syst.-I: Fundam. Theory Appl. 2002, 49, 383-387.

15. Wang, J.P.; Zhou, W.N.; Zhou, X.H. Chaos Control of Pulse-Disturbed Permanent Magnet Synchronous Motor with Uncertain Parameters. Trans. Inst. Meas. Control 2015, 8, 1-8. [CrossRef]

16. Sun, L.X.; Lu, S.; Wen, Z.G.; Li, Y.F. Analysis of Chaotic Motion Mechanism of Permanent Magnet Synchronous Motors. Electr. Mach. Control 2019, 23, 97-104.

17. Zhou, S.; Wang, D.Z.; Gao, Q.Z.; Liu, Y. Chaos Control of Permanent Magnet Synchronous Motor via Adaptive Sliding Mode Variable Structure Scheme. Int. J. Control. Autom. 2016, 9, 117-128. [CrossRef]

18. Hu, J.; Qiu, Y.; Lu, H. Adaptive Robust Nonlinear Feedback Control of Chaos in PMSM System with Modeling Uncertainty. Appl. Math. Modeling 2016, 40, 8265-8275. [CrossRef]

19. Gunasekaran, N.; Joo, Y.H. Stochastic Sampled-data Controller for T-S Fuzzy Chaotic Systems and Its Application. IET Control. Theory Appl. 2019, 13, 1834-1843. [CrossRef]

20. Jonscher, A.K. Dielectric Relaxation in Solids; Chelsea Dielectrics Press Ltd.: London, UK, 1983.

21. Westerlund, S.; Ekstam, L. Capacitor Theory. IEEE Trans. Dielectr. Electr. Insul. 1994, 1, 826-839. [CrossRef]

22. Daouac, R.A.Z.; Francisb, C.; Moreaua, X. Synthesis and Implementation of Non-integer Integrators using RLC Devices. Int. J. Electron. 2009, 96, 1207-1223.

23. Petras, I.; Chen, Y.Q.; Coopmans, C. Fractional-order Memristive Systems. In Proceedings of the IEEE Conference on Emerging Technologies \& Factory Automation, Palma de Mallorca, Spain, 22-25 September 2009.

24. Zheng, W.J.; Luo, Y.; Chen, Y.Q.; Pi, Y.G. Fractional-order Modeling of Permanent Magnet Synchronous Motor Speed Servo System. J. Vib. Control 2016, 22, 2255-2280. [CrossRef]

25. Xue, W.; Li, Y.L.; Cang, S.J.; Jia, H.Y.; Wang, Z.H. Chaotic Behavior and Circuit Implementation of a Fractional-order Permanent Magnet Synchronous Motor Model. J. Frankl. Inst. 2015, 352, 2887-2898. [CrossRef]

26. Lu, S.K.; Wang, X.C.; Wang, L.D. Finite-time Adaptive Neural Network Control for Fractional-order Chaotic PMSM via Command Filtered Backstepping. Adv. Differ. Equ. 2020, 121, 1-21. [CrossRef]

27. Guo, Y.X.; Ma, B.L. Asymptotic Stabilization of Fractional Permanent Magnet Synchronous Motor. J. Comput. Nonlinear Dyn. 2017, 9, 1-18. [CrossRef]

28. Wang, B.; Xue, J.Y.; Chen, D.Y. Takagi-Sugeno Fuzzy Control for a Wide Class of Fractional-order Chaotic Systems with Uncertain Parameters via Linear Matrix Inequality. J. Vib. Control 2016, 22, 2356-2369. [CrossRef]

29. Li, N.; Li, Y.G.; Wang, H.X.; Sun, Y.G. Fuzzy Tracking Control for Fractional-order Permanent Magnet Synchronous Motor Chaotic System. Inf. Control 2016, 45, 8-13.

30. Yang, G.L.; Li, H.G. Sliding Mode Variable-structure Control of Chaos in Direct-driven Permanent Magnet Synchronous Generators for Wind Turbines. Acta Phys. Sin. 2009, 58, 7552-7557.

31. Cao, N.; Shi, W.X.; Zhu, C.H. Simulated Analysis of Dynamic Characteristics of Permanent Magnet Direct-Drive Synchronous Wind Turbine Generators. Electr. Mach. Control 2017, 44, 104-109.

32. Yang, L.; Huang, T.M.; Deng, L.; Zeng, Y.F.; Huang, S.D. Analysis on Chaotic Mechanism of Direct-Drive Permanent Magnet Synchronous Generators based on Lyapunov Stability Theory. Eur. J. Electr. Eng. 2019, 21, 531-537. [CrossRef]

33. Zheng, G.; Zou, J.X.; Xu, H.B.; Qin, G. Adaptive Backstepping Control of Chaotic Property in Direct-Driven Permanent Magnet Synchronous Generators for Wind Power. Acta Phys. Sin. 2011, 60, 060506-060513. 
34. Zeng, Z.Z.; Liu, F. Nonlinear Proportional Control of Chaotic Property in Direct-Driven Permanent Magnet Synchronous Generators for Wind Turbine. J. Electr. Power Sci. Technol. 2014, 29, 29-36.

35. Wu, Z.Q.; Jia, W.J.; Zhao, L.R.; Wu, C.H. Maximum Wind Power Tracking for PMSG Chaos Systems-ADHDP Method. Appl. Soft Comput. 2015, 36, 204-209.

36. Wang, L.; Li, Y.H.; Lu, G.L.; Zhu, X.H. Tracking Controller of D-PMSG Chaos Motion. Electr. Power Autom. Equip. 2011, 31 , 45-49.

37. Si, G.Q.; Zhu, J.W.; Diao, L.J.; Ding, Z.Q. Modeling, Nonlinear Dynamic Analysis and Control of Fractional PMSG of Wind Turbine. Nonlinear Dyn. 2017, 88, 985-1000. [CrossRef]

38. Manashita, B.; Binoy, K.R. Dynamics of the Fractional-Order Chaotic PMSG, Its Stabilization using Predictive Control and Circuit Validation. IET Electr. Power Appl. 2017, 11, 707-716.

39. Karthikeyan, R.; Anitha, K.; Prakash, D. Chaos Suppression in Fractional Order Permanent Magnet Synchronous Generator in Wind Turbine. Nonlinear Eng. 2016, 11, 1-9.

40. Cantor, D.G. Computing in the Jacobian of a Hyperelliptic Curve. Math. Comput. 1987, 48, 95-101. [CrossRef]

41. Takagi, T.; Sugeno, M. Fuzzy Identification of Systems and Its Applications to Modeling and Control. IEEE Trans. Syst. Man Cybern. 1985, 15, 116-132. [CrossRef]

42. Krener, A.J. Approximate Linearization by State Feedback and Coordinate Change. Syst. Control. Lett. 1984, 5, 181-185. [CrossRef]

43. Li, Y.T.; Li, J.M. Stability Analysis of Fractional Order Systems Based on T-S Fuzzy Model with the Fractional Order $\alpha$ : $0<\alpha<1$. Nonlinear Dyn. 2014, 78, 2909-2919.

44. Wu, C. External Stability of Caputo Fractional-Order Nonlinear Control Systems: Advances in the Lyapunov Function Method. Nonlinear Dyn. 2021, 104, 429-438. [CrossRef]

45. Fan, X.F.; Wang, Z.S. A Fuzzy Lyapunov Function Method to Stability Analysis of Fractional Order T-S Fuzzy Systems. IEEE Trans. Fuzzy Syst. 2021. [CrossRef]

46. Tidjani, N.; Guessoum, A. Augmented Robust T-S Fuzzy Control Based PMSG Wind Turbine Improved with $\mathrm{H}_{\infty}$ Performance. Int. J. Power Electron. Drive Syst. 2021, 12, 585-596.

47. Mani, P.; Rajan, R.; Joo, Y.H. Design of Observer-Based Event-Triggered Fuzzy ISMC for T-S Fuzzy Model and Its Application to PMSG. IEEE Trans. Syst. Man Cybern. Syst. 2021, 51, 2221-2231. [CrossRef]

48. Hwang, S.; Park, J.B.; Joo, Y.H. Disturbance Observer-Based Integral Fuzzy Sliding-Mode Control and Its Application to Wind Turbine System. IET Control. Theory Appl. 2019, 13, 1891-1900. [CrossRef]

49. Herissi, B.; Boudjehem, D. Fractional-Order Fuzzy Controller for a PMSG Wind Turbine System. Int. J. Syst. Sci. 2020, 51, 3237-3250. [CrossRef]

50. Mani, P.; Rajan, R.; Shanmugam, L.; Joo, Y.H. Adaptive Fractional Fuzzy Integral Sliding Mode Control for PMSM Model. IEEE Trans. Fuzzy Syst. 2019, 27, 1674-1686. [CrossRef]

51. Xue, D.Y. Fractional Calculus and Fractional-Order Control; Science Press: Beijing, China, 2018.

52. Xie, L.H. Output Feedback $H_{\infty}$ Control of Systems with Parameter uncertainty. Int. J. Control. 1996, 63, 741-750. [CrossRef]

53. Boyd, S.; EL, G.L.; Feron, E.; Balakrishnan, V. Linear Matrix Inequalities in System and Control Theory; Society for Industrial and Applied Mathematics: Philadelphia, PA, USA, 1994.

54. Li, Y.; Chen, Y.Q.; Podlubny, I. Stability of Fractional-Order nonlinear Dynamic Systems: Lyapunov Direct Method and Generalized Mittag-Leffler Stability. Comput. Math. Appl. 2010, 59, 1810-1821. [CrossRef]

55. Li, Y.T. Stability and Stabilization of Fractional Order Systems Based on Takagi-Sugeno Fuzzy Model; Xidian University: Xi'an, China, 2015.

56. Tavazoer, M.S.; Haeri, M. Chaotic Attractors in Incommensurate Fractional Order Systems. Phys. D 2008, 237, 2628-2637. [CrossRef]

57. Rauh, A.; Seelert, W. The Betz Optimum Efficiency for Windmills. Appl. Energy 1984, 17, 15-23. [CrossRef]

58. Ye, H.Y. Control Technology of Wind Turbine; China Machine Press: Beijing, China, 2015.

59. Zhou, K.; Ai, M.; Sun, D.Y.; Jin, N.Z.; Wu, X.G. Field Weakening Operation Control Strategies of PMSM Based in Feedback Linearization. Energies 2019, 12, 4526. [CrossRef]

60. Smarandache, F. A Unifying Field in Logics: Neutrosophic Logic. Neutrosophy, Neutrosophic Set, Neutrosophic Probability; American Research Press: Santa Fe, NM, USA, 1998.

61. Smarandache, F. Introduction to Neutrosophic Statistics; Infinite Study; Sitech \& Education Publishing: Columbus, OH, USA, 2014.

62. Hefenawy, N.E.; Metwally, M.A.; Ahmed, Z.M.; Henawy, I.M. A Review on the Applications of Neutrosophic Sets. J. Comput. Theor. Nanosci. 2014, 13, 936-944. [CrossRef]

63. Aslam, M.; Bantan, R.A.R.; Khan, N. Design of a New Attribute Control Chart under Neutrosophic Statistics. Int. J. Fuzzy Syst. 2019, 21, 433-440. [CrossRef]

64. Aslam, M. A New method to analyze rock joint roughness coefficient base on Neutrosophic Statistics. Measurement 2019, 146, 65-71. [CrossRef]

65. Aslam, M.; Arif, O.H.; Sherwani, R.A.K. New Diagnosis Test under the Neutrosophic Statistics: An Application to Diabetic Patients. Biomed Res. Int. 2020. [CrossRef] [PubMed]

66. Fu, Z.L.; Liu, C.P.; Ruan, S.Y.; Chen, K. Design of Neutrosophic Self-Tuning PID Controller for AC Permanent Magnet Synchronous Motor Based on Neutrosophic Theory. Math. Probl. Eng. 2021. [CrossRef] 